\title{
PROSPECTS
}

\section{Speak up}

\section{Peter Fiske argues that too many young scientists adopt a passive voice, to the detriment of their careers.}

When I was in graduate school studying geology and environmental sciences, many of my professors insisted that we students write our manuscripts in the passive voice: "This was done" rather than "I did this". They reasoned that removing the agent from the description of the action lent an objective tone. As scientists, we stood apart from our work and encouraged others to critique it (rather than us).

Today, teachers are much more likely to advocate use of the active voice in manuscripts. In general, the active voice is more readable and engaging, which can be particularly helpful in light of the sometimes turgid prose of scientific papers.

In the years since I moved from academic science to business, young scientists have started to adopt a more active tone in their manuscripts. Still, the culture of science still seems to encourage a 'passive voice' in much of the rest of their careers. Peers and mentors often imply that they should remain at the bench rather than actively reach out to potential sponsors, supporters and collaborators. Young scientists think that doing good science will be enough to advance their careers. "If you're the best, you'll get a job" is the assurance they receive.

\section{Modesty or arrogance?}

In life, as in writing, a passive approach may be intended to suggest a degree of objectivity. Avoiding the appearance of 'selfpromotion' may seem desirable for establishing credibility. But failure to make any attempt to advocate for oneself and one's abilities can be misinterpreted as indifference, even arrogance.

Collaboration is a case in point. Working with researchers in other departments and institutions is by far the most effective way for young scientists to advance their careers. Yet few PhD and postdoc advisers encourage their charges to pursue any such partnerships. Understandably, PhD advisers may worry that their students will lose focus by working outside their research group. But some resist simply because letting students engage in outside work would mean fewer hands in the lab. PhD and postdoc advisers have lots of influence, and this can lead to a pattern of passivity among young scientists. As a result, few of them pursue such collaborations on their own.

This 'passive voice' also arises when engaging in professional networking. Most scientists recognize that networking with colleagues has a crucial role in career development. But rather than proactively reaching out to others, many wait to receive such gestures. Networking is both acceptable and valued in the business world,
Scientists must communicate about their work - to other scientists, sponsors of their research and the general public. Active communication means more than merely accepting invitations to give talks at other institutions. An 'active voice' in communication means searching for opportunities to give talks and lectures — and seeking audiences that are outside one's immediate sphere of scientific influence at, for example, science museums or local

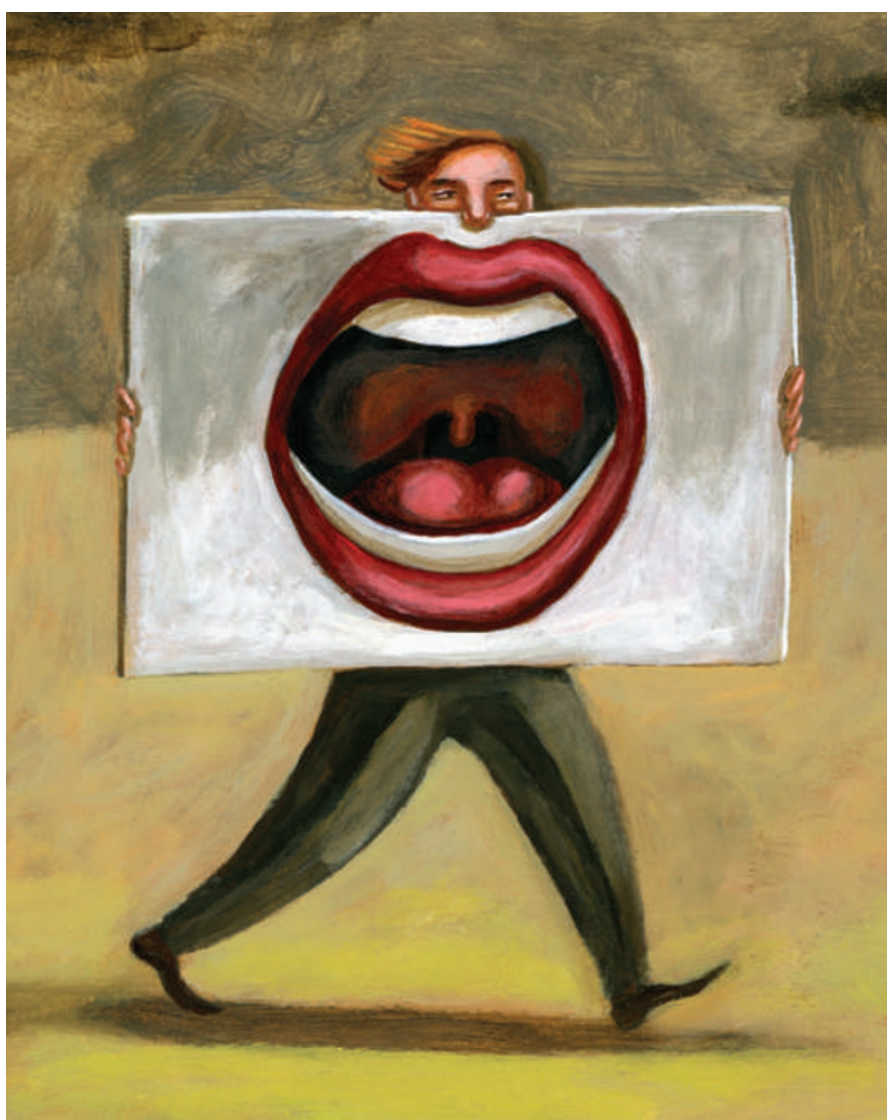

but many scientists and engineers view it as 'schmoozing'. Those who try to forge close ties to their administration or financial sponsors may earn a reputation for being 'political' among jealous colleagues. Younger scientists witness this pathological behaviour and quickly absorb the lesson: 'true' scientists are above networking.

Although scientists may increasingly write their papers in the active voice, the way they promote their work often remains passive. Scientists expect their publications to communicate for them. A large body of scholarly work certainly confers a degree of authority and knowledge. But even the bestwritten papers never completely capture the passion and insight that led to their creation. civic organizations.

\section{Public perceptions}

Scientists may also have passive attitudes towards political advocacy. Many scientists are incredulous at how little the general public knows about science and technology.

A survey carried out by the Pew Research Center for the People and the Press in Washington DC last July found that $85 \%$ of US scientists interviewed saw the public's lack of knowledge as a major problem for science. Half of them fault the public for having a poor understanding of the pace of scientific discovery.

But scientists do little to address the gap in understanding. Most think that their successes in the lab are manifestly evident, making education about the value of their work unnecessary. Few ever communicate with their elected officials. With the public footing most of the bill, this misguided belief seems naive and undermines those who campaign for more funding.

In a global recession, taking a passive career approach poses an increasing disadvantage. Stronger competition for a finite number of research positions will favour those who combine outstanding work with an ability to engage their communities and constituencies. Excellent work is a prerequisite for career progress, but is not sufficient by itself. Broadcasting one's accomplishments and exercising the 'active voice' in all aspects of one's work is the best way to earn notice, gain recognition and make the public at large aware of the value of the scientific enterprise.

Peter Fiske is chief technology officer of PAX Water Technologies in San Rafael, California, and author of Put Your Science to Work (American Geophysical Union, 2001). 